\title{
Punching Shear Capacity Analysis of Reinforced Concrete Slab-column Connections
}

\author{
Huiyong Guo ${ }^{1,2, a^{*}}$, Jinjun Cheng ${ }^{1,2, b}$ \\ ${ }^{1}$ School of civil Engineering, Chongqing University, Chongqing 400045, P. R. China \\ ${ }^{2}$ Key Laboratory of New Technology for Construction of Cities in Mountain Area of the Ministry of \\ Education, Chongqing 400045, China \\ aghy267@tom.com, ${ }^{\text {b}} 527122168 @ q q . c o m$
}

Keywords: reinforcement concrete; slab-column connections; punching shear performance; finite element analysis; longitudinal reinforcement ratio.

Abstract. In order to solve punching shear strength problem of reinforced concrete slab-column connections, an improved punching shear capacity formula is presented. First, punching shear capacity of reinforced concrete slab-column connections is analyzed. Then, a comparison of punching shear capacity calculation methods is studied based on the codes: GB50010-2010, ACI318-08 and EN1992-1-1-2004. The effect of longitudinal reinforcement ratio is analyzed by using ANSYS finite element software. Finally, an improved punching shear capacity formula is proposed. The results indicate that because of the consideration of longitudinal reinforcement ratio, the calculation capacity of the improved punching shear capacity formula is more reasonable.

\section{Introduction}

The flat slab structure is also called as slab-column structure, which has good economic advantage of effectively reduced storey and can take full use of the housing space. However, a flat plate is susceptible to punching shear failure at its slab-column connection. This punching shear failure significantly degrades the overall resistance of the structure against gravity load, and thus the structure may collapse. For this reason, many studies have been performed to evaluate the punching shear strength of slab-column connections. Theodorakopoulos et al [1] presented a simple analytical model to predict the ultimate punching shear strength of slab-column connections. The model is based on the physical behavior of the connections under load, and is therefore applicable to both lightweight and normal weight concrete. Choi et al [2] performed a theoretical study to investigate the punching shear strength of interior slab-column connections made of steel fiber reinforced concrete. Park et al [3] developed a strength model to predict the direct punching shear strength of interior slab-column connections without shear reinforcement. At slab-column connections damaged by flexural cracking, it was assumed that the punching shear force was resisted mainly by the compression zone of the critical section. Abdullah et al [4] investigated the effectiveness of bonding non-prestressed and prestressed carbon fiber reinforced polymer plates to the tension surface of concrete column-slab connections in both the serviceability and ultimate limit state. However, the punching shear capacity calculation methods of several national building codes are different, the punching failure mechanism is still not clear yet. Especially the effect of longitudinal reinforcement ratio isn't considered in our codes GB50010-2010. Therefore, the punching shear calculation method of reinforced concrete slab-column connections is studied in this paper.

\section{Punching shear capacity}

Punching shear performance of slab around the joint area of reinforced concrete slab-column structure is very important. Here, we just consider the punching shear capacity of reinforced concrete slab without stirrup or bent-up reinforcement. Different punching shear capacity calculation methods are proposed by these codes[5]: GB50010-2010 (China), ACI318-08 (USA) and EN1992-1-1-2004 (Europe). For these codes, the punching shear capacity formula can be simply written as

$$
V_{c}=C_{0} \eta \mu_{m} h_{0}
$$


in which, $C_{0}$ is punching shear coefficient; $\eta=\min \left(\eta_{1}, \eta_{2}\right) ; \mu_{m}$ is critical section perimeter; $h_{0}$ is sectional effective height. For different codes, the punching shear coefficient $C_{0}$ and influence coefficient $\eta$ are listed in Table 1.

Table 1. Calculating parameters of punching shear capacity without abdominal reinforcement

\begin{tabular}{cccc} 
Codes & $C_{0}$ & $\eta_{1}$ & $\eta_{2}$ \\
\hline GB50010-2010 & $0.7 \beta_{h} f_{t}$ & $0.4+\frac{1.2}{\beta_{s}}$ & $0.5+\frac{\alpha_{s} h_{0}}{4 \mu_{m}}$ \\
ACI318-08 & $0.333 \lambda \phi \sqrt{f_{c}^{\prime}}$ & $0.5+\frac{1}{\beta_{s}}\left(\beta_{s} \geq 2\right)$ & $0.5+\frac{\alpha_{s} d}{4 b_{0}}$
\end{tabular}

EN1992-1-1-2004 $C_{R d, c} k\left(100 \rho_{1} f_{c k}\right)^{1 / 3} \geq v_{\min }+0.1 \sigma_{c p}$

in which, $f_{t}$ is concrete tensile strength, $f_{c}^{\prime}$ is concrete compressive strength, $f_{c k}$ is standard value of concrete compressive strength, $\beta_{h}$ is influence coefficient of sectional height, $\beta_{s}$ is long side to short side ratio, $\alpha_{s}$ is influence coefficient of column type.

In general, the punching shear capacity is related to many influencing factors such as concrete strength, shape of loading area, longitudinal reinforcement ratio, anti-punch reinforcement placing etc. For different codes, the main influencing factors are listed in Table 2.

Table 2. Main factors in different national codes

\begin{tabular}{cccc}
\hline influencing factors & GB50010-2010 & ACI318-08 & EN1992-1-1-2004 \\
\hline concrete strength & $f_{t}$ & $f_{c}^{\prime}$ & $f_{c k}$ \\
shape of loading area & Yes & Yes & No \\
perimeter-height ratio & Yes & Yes & No \\
longitudinal reinforcement ratio & No & No & Yes \\
punching shear cone angle and critical & $45^{\circ}$ or $\frac{h_{0}}{2}$ & $45^{\circ}$ or $\frac{d}{2}$ & $14^{\circ}$ or $2 d$ \\
width & &
\end{tabular}

From Table 2, it can be seen that the effect of longitudinal reinforcement ratio hasn't been considered in the code GB50010-2010 and code ACI318-08. The code EN1992-1-1-2004 considers the effect of longitudinal reinforcement ratio but doesn't consider the shape of loading area and perimeter-height ratio. Therefore, it is necessary to improve the punching shear capacity formula.

\section{Calculation analysis}

A reinforced concrete slab-column connection structure is considered in this paper. In the connection structure, slab depth $h=200 \mathrm{~mm}$, column size $a \times b=350 \mathrm{~mm} \times 350 \mathrm{~mm}$, concrete strength is C30, two-way longitudinal reinforcement configuration is $\Phi 12 @ 100$, reinforcement area per metre is $A_{s}=1131 \mathrm{~mm}^{2}$, steel reinforcement strength standard value is $335 \mathrm{MPa}$.

ANSYS finite element software is applied to calculate the punching shear capacity of reinforced concrete slab-column connection. The results of numerical calculations are shown in Figure 1 with the longitudinal reinforcement ratio plotted against the capacity value. From Figure 1, it can be observed that the longitudinal reinforcement ratio doesn't have an effect on punching shear capacity for the codes GB50010-2010 and ACI318-08. In addition, it has a linear change for the code EN1992-1-1-2004. The punching shear capacity value of the code GB50010-2010 is lowest in the three codes. Therefore, the code GB50010-2010 is more conservative than the code ACI318-08 and code EN1992-1-1-2004. Thus, it is necessary to consider the effect of longitudinal reinforcement ratio. 


\section{Improved punching shear capacity equation}

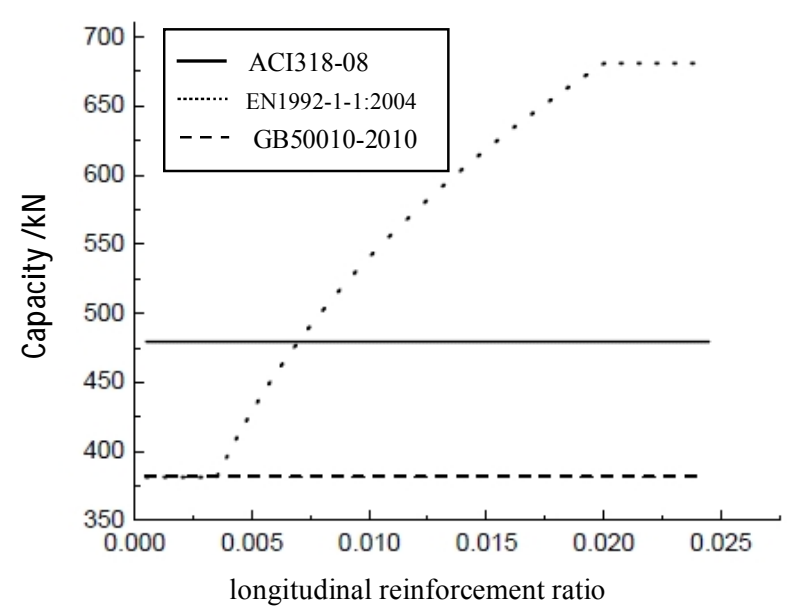

Fig. 1. Influence curve of longitudinal reinforcement ratio

In our code GB50010-2010, the effect of longitudinal reinforcement ratio isn't considered. Thus, the calculation value is too conservative. Through the comparison of punching shear capacity formulas of the three codes: GB50010-2010, ACI318-08 and EN1992-1-1-2004, it can be seen that the punching shear capacity should include four main parts: correction coefficient, influence coefficient, concrete strength, and critical section area. Thus,

$$
V_{c}=\gamma f \mu_{m} h_{0}
$$

In order to solve the problem that the punching shear capacity and the longitudinal reinforcement ratio are uncorrelated in our code GB50010-2010, the punching shear capacity equation should be improved. In the code EN1992-1-1-2004, the punching shear capacity is proportional to $\rho^{1 / 3}$. Therefore, we can use the fitting equation form $y=a x^{b}$, in which, $x$ is reinforcement ratio, $y$ is punching shear capacity. The fitting results are shown in Figure 2 and Figure 3.

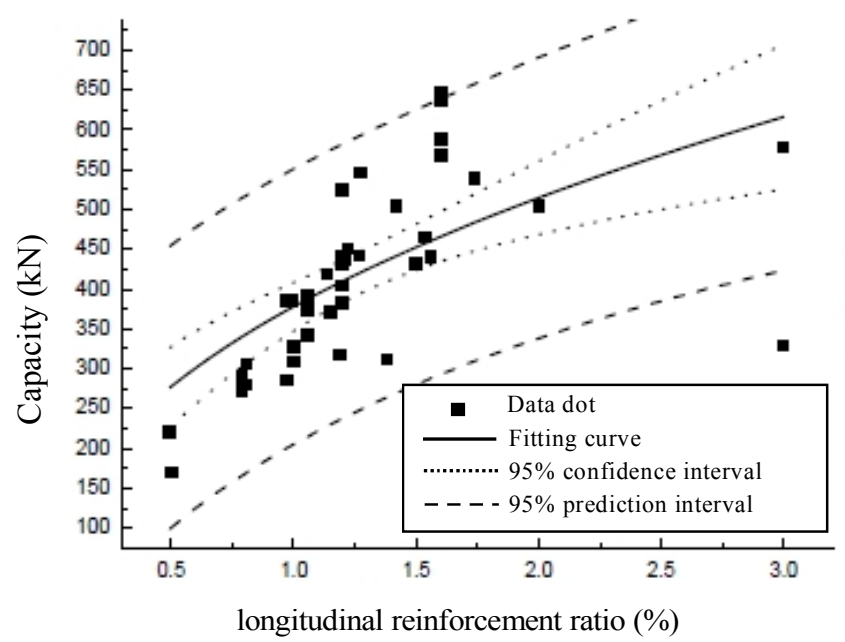

Fig. 2. Fitting curve of the equation

The fitting value of $b$ is 0.445 , the correlation coefficient is 0.659 . It can be seen that the fitting correlation coefficient is close to that of the code EN1992-1-1:2004. Thus, the influence coefficient of longitudinal reinforcement ratio can be given by

$$
\xi=\left(100 \rho_{L}\right)^{0.445}
$$

In order to avoid the calculation result of $\xi$ is less than that of the old codes, it is required that $\xi \geq 1$ . Thus, the improved punching shear capacity can be written as

$$
V_{c}=0.7 \beta_{h} \xi_{t} \eta \mu_{m} h_{0}
$$


in which, $\eta=\min \left\{\eta_{1}, \eta_{2}\right\}, \eta_{1}=0.4+\frac{1.2}{\beta_{s}}, \eta_{2}=0.5+\frac{\alpha_{s} h_{0}}{4 \mu_{m}}$

$$
\xi=\left\{\begin{array}{cc}
1 & \rho_{L} \leq 0.01 \\
\left(100 \rho_{L}\right)^{0.445} & \rho_{L}>0.01
\end{array}\right.
$$

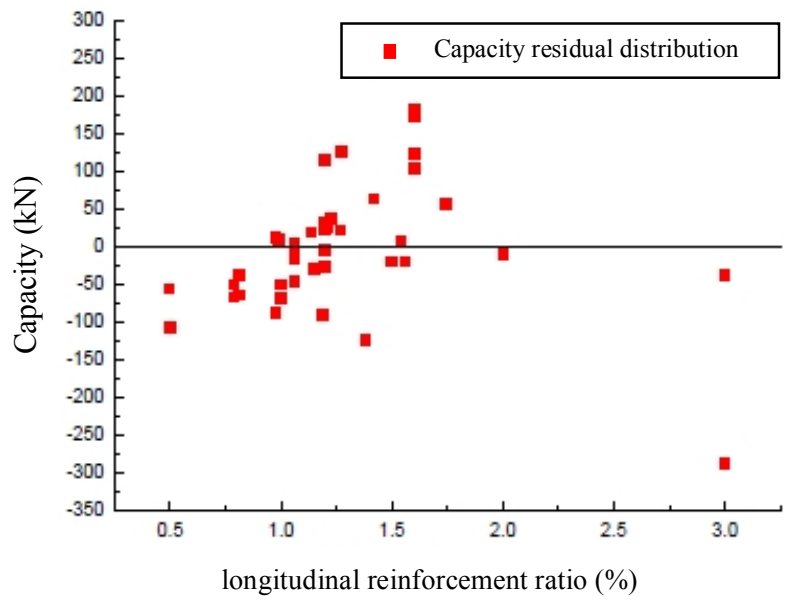

Fig. 3. Residual distribution

\section{Conclusions}

In this paper, a comparison study of punching shear capacity based on GB50010-2010, ACI318-08 and EN1992-1-1-2004, is performed and an improved punching shear capacity formula is presented. By taking into account the analysis results of the reinforced concrete slab-column connections, the following conclusions can be drawn: (1) The codes GB50010-2010 and ACI318-08 don't consider the effect of longitudinal reinforcement ratio for punching shear capacity. (2) The code EN1992-1-1-2004 considers the effect of longitudinal reinforcement ratio but doesn't consider the effect of loading area shape and perimeter-height ratio. (3) The improved punching shear capacity formula considers not only the effect of longitudinal reinforcement ratio but also the effect of loading area shape. Therefore, the improved punching shear capacity formula is closer to the fact of reinforced concrete slab-column connections.

\section{Acknowledgments}

Project supported by Construction science and technology Foundation of Chongqing (Grant No. 2014-0005) and supported by the National Natural Science Foundation of China (Grant No. 51468058).

\section{References}

[1] D.D. Theodorakopoulos, R.N. Swamy. Ultimate punching shear strength analysis of slab-column connections, Cement \& Concrete Composites, 24(2002) 509-521.

[2] K.K. Choi, M.M.R. Taha, H.G. Park et al. Punching shear strength of interior concrete slab-column connections reinforced with steel fibers, Cement \& Concrete Composites, 29(2007) 409-420.

[3] H.G. Park, K.K. Choi, L. Chung. Strain-based strength model for direct punching shear of interior slab-column connections, Engineering Structures,, 33(2011) 1062-1073.

[4] A. Abdullah, C.G. Bailey, Z.J. Wu. Tests investigating the punching shear of a column-slab connection strengthened with non-prestressed or prestressed FRP plates, Construction and Building Materials, 48(2013) 1134-1144. 
[5] Ministry of housing and urban-rural development of the People's Republic of China. Code for design of concrete structures (GB50010-2010), China Architecture \& Building Press, Beijing, 2010. 